\title{
Normas y procedimientos para una auditoría externa a estados financieros en el Ecuador
}

\section{Rules and Procedures for an External Audit of \\ Financial Statements in Ecuador}

CARLOS MANCHENO VACA

Universidad Tecnológica Equinoccial

Correo electrónico: carlos.mancheno@ute.edu.ec

RECIBIDO: 01/10/2015

APROBADO: $16 / 11 / 2015$

\section{Resumen}

La Auditoría se ha convertido en la actualidad en un aliado de las empresas ante posibles fuentes de distorsión financiera. Los fraudes laborales y corporativos conllevan un alto riesgo para: inversionistas, accionistas, clientes internos, clientes externos, proveedores y el Estado. Sobre esta base, las organizaciones contratan auditores internos y externos, quienes deben cumplir requisitos fundamentales como: experiencia, independencia, confidencialidad e integridad. Ante posibles fraudes, los auditores internos son los encargados de monitorear permanentemente los posibles desvíos ajenos a las operaciones económicas de la organización, su función es monitorear el control interno y los riesgos existentes, informando oportunamente sobre situaciones como jineteo de fondos ${ }^{1}$; desvío de fondos; sobre y subestimación de activos y pasivos; entre otros. Es distinto el alcance de una auditoría externa, porque su objetivo es emitir una opinión sobre la razonabilidad de saldos y el cumplimiento de principios y normas que rigen la aplicación contable y financiera en las empresas, emitiendo informes que deben ser presentados a la Superintendencia de Compañías y al Servicio de Rentas Internas.

1 Es un término figurado que se utiliza en el medio contable - financiero para identificar el aprovechamiento transitorio, pero indebido, de fondos que pertenecen a una persona distinta a la cual los retiene en beneficio. Whittington Penny (2009) 


\section{Summary}

The Audit has become an ally of companies and entrepreneurs to possible sources of financial distortion such as labor and corporate fraud that carry a high risk for information users such as: investors, shareholders, internal or external customers, suppliers and the State, on this basis the organizations hire both internal and external Auditors who must meet certain fundamental requirements such as experience, independence, confidentiality and integrity; In the face of possible fraud, those who would be responsible for permanently monitoring departures from the organization's economic operations are the internal auditors, since their position is to monitor internal control and existing risks, timely reporting on situations such as hockey, Of funds, over and underestimation of assets and liabilities, among others. The scope of an external audit is different since its focus and objective is to express an opinion on the reasonableness of balances and compliance with principles and rules governing accounting and financial application in companies, issuing reports that must be presented to Control agencies such as the Superintendency of Companies and the Internal Revenue Service.

PALABRAS CLAVES: Auditoría, control.

KEYWORDS: Financial Audit, control.

CLASIFICACIÓN JEL: M42, M48

\section{Introducción}

En Ecuador, la auditoría externa a estados financieros, se rige por organismos de control como la Superintendencia de Compañías, de aquí en adelante SC, como por la Superintendencia de Bancos y Seguros; para este estudio solo analizaremos las controladas por la SC.

La auditoría externa en su definición más tradicional, sería el servicio prestado por profesionales calificados en contabilidad, consistente en la revisión de los estados financieros de una empresa, según normas y técnicas específicas, a fin de expresar su opinión independiente sobre la situación económica-contable-financiera de dicha empresa en un momento dado, sus resultados y los cambios en ella habidos durante un período determinado, de acuerdo con los principios contables generalmente aceptados. (Barroja, 2002).

La auditoría tiene por objeto averiguar la exactitud, integridad y autenticidad de los estados financieros, expedientes y demás documentos administrati- 
vo-contables presentados por la dirección, así como sugerir las mejoras administrativo-contables que procedan. (Madariaga, 2004, p.15)

La auditoría externa se encuentra establecida como obligatoria por la Ley de Compañías, afecta a las empresas constituidas como Compañía Limitada o sociedades, y que tengan o superen el monto de US\$ 1'000.000,00 de dólares en los activos totales del ejercicio económico anterior. Es importante mencionar que la auditoría externa efectuada a las empresas, constituye un soporte importante para el área financiera de las mismas porque fomenta buenas prácticas contables, asesorando a la alta dirección sobre situaciones que deriven de una mala aplicación y adopción de las normas vigentes.

Sobre la base de la resolución No 02.Q.ICI.004 del 26 de marzo de 2002, que posteriormente fue modificada con la resolución de julio de 2002 y publicada en el Registro Oficial No 621 de fecha 15 de julio de 2002. Es obligatoria la auditoría externa a:

\section{Tabla 1.}

Obligatoriedad en montos para una Auditoría Externa

\begin{tabular}{|l|l|}
\hline Tipo de Compañías & Base de Activos \\
\hline $\begin{array}{l}\text { Las compañías nacionales de } \\
\text { economía mixta y las anónimas con } \\
\text { participación de personas jurídicas de } \\
\text { derecho público o de derecho privado } \\
\text { con finalidad social o pública. }\end{array}$ & US\$100.000,00 \\
\hline $\begin{array}{l}\text { Las sucursales de compañías o } \\
\text { empresas extranjeras organizadas } \\
\text { como personas jurídicas que se } \\
\text { hubieran establecido en el Ecuador y } \\
\text { las asociaciones que estas formen } \\
\text { entre sí o con compañías nacionales. }\end{array}$ & US $100.000,00$ \\
\hline $\begin{array}{l}\text { Las compañías nacionales anónimas, } \\
\text { en comandita por acciones y de } \\
\text { responsabilidad limitada. }\end{array}$ & US\$ 1.000.000,00 \\
\hline
\end{tabular}

Fuente: Articulo 321 Ley de Compañías del Ecuador Elaborado por: Carlos Mancheno Vaca
Para efectos de determinación de la base para la obligación de auditoría, se considera el monto de activos del ejercicio económico anterior de acuerdo con el siguiente ejemplo:

Tabla 2.

Base para la obligación de Auditoría externa

\begin{tabular}{|c|c|}
\hline $\begin{array}{c}\text { Total activos } \\
\text { 31 de diciembre de } 2014\end{array}$ & Obligatoriedad \\
\hline US\$ 1.000 .000 & Tiene obligación \\
\hline US\$ 500.000 & No tiene obligación \\
\hline US\$ 999.999 & No tiene obligación \\
\hline
\end{tabular}

Elaborado por: Carlos Mancheno Vaca

De acuerdo con esta resolución se establece cuáles son las empresas que se encuentran en la obligatoriedad de efectuar una auditoría externa de sus estados financieros. Es importante mencionar que en la actualidad los auditores externos se constituyen en asesores-consultores, brindan el soporte indispensable para el funcionamiento de los departamentos financieros de las organizaciones. Existen compañías que no se encuentran obligadas, de acuerdo con la resolución citada, a ser sujetas de auditoría externa; sin embargo, estas proceden a contratar firmas de auditoría para que revisen sus estados financieros y colaboren en la identificación y corrección de errores, ya sean contables o tributarios.

Una auditoría puede ser: externa, interna o tributaria.

La auditoría externa requiere conocer los procedimientos internos establecidos en cada uno de los departamentos de las organizaciones con la finalidad de 
Tabla 3.

Tipos de Auditoría

\begin{tabular}{|l|l|}
\hline TIPOS DE AUDITORÍA & \multicolumn{1}{c|}{ DEFINICIÓN } \\
\hline Auditoría Externa & $\begin{array}{l}\text { Realizada por personal indepen- } \\
\text { diente, firmas y personas } \\
\text { naturales calificadas por la SC }\end{array}$ \\
\hline Auditoría Interna & $\begin{array}{l}\text { Realizada por un trabajador } \\
\text { asesor de la empresa }\end{array}$ \\
\hline Auditoría Tributaria & $\begin{array}{l}\text { Realizada por el Servicio de } \\
\text { Rentas Internas, puede ser } \\
\text { ejecutada por una firma auditora } \\
\text { como preventiva }\end{array}$ \\
\hline
\end{tabular}

Elaborado por: Carlos Mancheno Vaca evaluar sí el control interno cumple con los canales apropiados; y si estos se encuentran diseñados adecuadamente, en sentido de salvaguardar los activos de las empresas. Debido al proceso de implementación y adopción de las Normas Internacionales de Información Financiera NIIF en el Ecuador, existió un cambio fundamental para las auditorías externas, ya que en la actualidad su trabajo debe estar contemplado y basado con las Normas Internacionales de Auditoría y Aseguramiento para el ejercicio profesional, tomado del Registro Oficial No. 348 (04 de septiembre del 2006).

Cabe indicar que las Normas de Auditoría se clasifican en tres categorías: Normas personales, Normas relativas al trabajo y Normas relativas al informe.

Figura 1:

Clasificación de las Normas de Auditoría

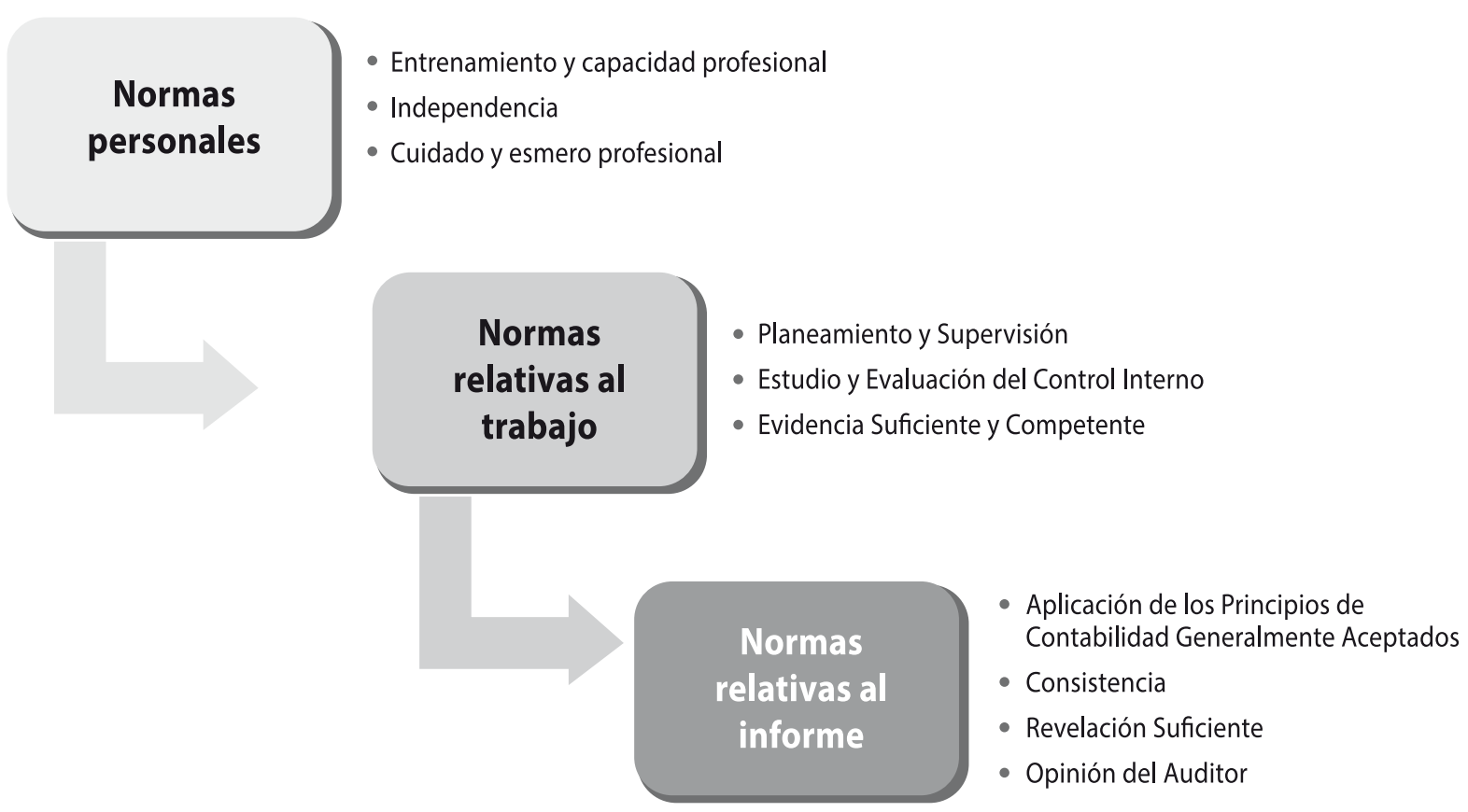


El proceso de globalización, en el cual Ecuador se encuentra inmerso, tiene efectos directos e indirectos dentro de la economía del país. Es importante que el auditor externo evalúe todos los factores que puedan afectar a una empresa en desarrollo, evaluando el riesgo inherente del negocio, y consecuentemente los Estados Financieros que presentan al cierre de un ejercicio económico establecido; su trabajo debe estar acorde con las Normas Internacionales de Auditoría y Aseguramiento y las Normas de Auditoría Generalmente Aceptadas conocidas en la rama como las NAGA.

La auditoría externa tiene la finalidad de diseñar estrategias adecuadas para las industrias y además evaluar los factores internos y externos que pueden modificarla, esto permite determinar el riesgo combinado que podría afectar a los Estados Financieros, y por ende, evaluar su control interno. El auditor debe establecer procedimientos de auditoría que disminuyan el riesgo en la ejecución de su trabajo hasta la fecha de presentación del informe auditado. Las firmas de auditoría externa deben tener claros los procedimientos de la normativa vigente: planificación, ejecución del trabajo y comunicación de resultados.
Planificación.- Antes de iniciar el trabajo, el auditor debe obtener un conocimiento preliminar de la industria; del grupo de accionistas; de la administración y de las operaciones de la entidad que va a ser auditada. Evaluará si la información recabada del negocio es suficiente para iniciar la auditoría (Norma Internacional de Auditoría NIA - 310).

Una vez iniciado el trabajo se debe obtener información en mayor detalle. A medida que avanza la auditoría, la información será permanentemente evaluada y, actualizada. La obtención del conocimiento acerca del negocio es un proceso continuo y acumulativo de recolección y evaluación de la información; además de relacionar el conocimiento adquirido con la evidencia de auditoría e información en todas las etapas de la auditoría. Si bien la información se reúne con mayor intensidad en la etapa de planeación de la auditoría, esta seguirá afinándose y complementando en etapas posteriores, gracias al mayor conocimiento del negocio por parte del equipo auditor.

En esta etapa se considera la evaluación del riesgo, enfatizando el enfoque de auditoría, por tal razón el auditor debe medir y evaluar lo siguiente:

Tabla 4.

Tipos de riesgo en Auditoría Externa

\begin{tabular}{|c|l|}
\hline TIPO DE RIESGO & \multicolumn{1}{c|}{ DEFINICIÓN } \\
\hline Riesgo Inherente & $\begin{array}{l}\text { Posibilidad de errores o irregularidades (fraude) en la información financiera SIN } \\
\text { considerar el control interno. }\end{array}$ \\
\hline Riesgo de Control & $\begin{array}{l}\text { Posibilidad de errores o irregularidades (fraude) en la información financiera } \\
\text { A PESAR del control interno. }\end{array}$ \\
\hline Riesgo de detección & $\begin{array}{l}\text { Posibilidad de errores o irregularidades (fraude) en la información financiera } \\
\text { A PESAR de los procedimientos de Auditoría. }\end{array}$ \\
\hline Riesgo de Auditoría & $\begin{array}{l}\text { Posibilidad de emitir un dictamen inadecuado a consecuencia de errores en la } \\
\text { aplicación de pruebas de cumplimiento y/o pruebas sustantivas. }\end{array}$ \\
\hline
\end{tabular}

Fuente: A, Aud Fin Desarrollo Materia, J. Badillo, Sept 09

Elaborado por: Carlos Mancheno Vaca 
En estos cuatro tipos de riesgo manejados en la planificación (Tabla 4) se miden el riesgo inherente y el riesgo de control.

La planeación de la auditoría es la fase inicial del examen y consiste en determinar de manera anticipada los procedimientos que se van a utilizar, la extensión de las pruebas que se van a aplicar, la oportunidad de las mismas, los diferentes papeles de trabajo en los cuales se resumirán los resultados y los recursos humanos y físicos que se deberán asignar para lograr los objetivos propuestos de la manera más eficiente.

Existen dos planificaciones: la preliminar reúne el conocimiento acumulado del ente, y la planificación específica que determina los procedimientos que serán utilizados para analizar la documentación e información recopilada.

Ejecución del trabajo.- La ejecución del trabajo, es la aplicación de los procedimientos descritos en los programas de auditoría. Aquí el auditor realiza pruebas: globales, de cumplimiento y sustantivas. De la misma forma el profesional ejecuta técnicas de auditoría que le ayudarán en sus pruebas. Norma Internacional de Auditoría NIA - 320.

Pruebas globales: estas pruebas fomentan el mejor conocimiento del negocio y sirven para identificar áreas consideradas como críticas. El auditor efectúa análisis comparativo de estados financieros, análisis de índices financieros, análisis de ejecuciones presupuestarias, entre otros.

Pruebas de cumplimiento: las pruebas de cumplimiento tienen como objetivo evaluar el control interno en las organizaciones. Normalmente las firmas realizan estas pruebas entre los meses de octubre y diciembre. Se utilizan como herramientas de medición: "check list", flujo gramas, cuestionarios, narrativas; estas pruebas evidencian la frecuencia de cometimiento de errores por insuficiencia de controles, estas no se refieren a valores sino, a la permanente desviación del cumplimiento de procedimientos contables como registros, recaudaciones, proveedores, nómina, bancos, entre otros. Culminado este proceso se entrega a los directivos de la organización la "Carta a Gerencia", informe que recoge las observaciones y recomendaciones evidenciadas en esta etapa.

Pruebas sustantivas: su objetivo es comprobar la validez de los saldos de las cuentas contables que se presentan en los estados financieros. Aquí se comprueba la existencia de activos y pasivos, la propiedad de los activos y pasivos, la correcta valoración de activos y pasivos, la adecuada presentación de las cuentas en los estados financieros, que las cuentas de ingreso y gasto estén registradas adecuadamente en el período financiero correcto. Estas pruebas se aplican a una fecha determinada sobre el análisis efectuado basado en un muestreo de auditoría. Las firmas de auditoría efectúan estas pruebas entre los meses de enero a marzo normalmente.

La Norma Internacional de Auditoría NIA - 12 Procedimientos Analíticos define a las pruebas de cumplimiento y sustantivas como:

"Pruebas de control se realizan para obtener evidencia de auditoría sobre la efectividad de:

(a) El diseño de los sistemas de contabilidad y de control interno, o sea, si están planeados adecuadamente para prevenir o detectar $y$ corregir representaciones erróneas de importancia relativa; $y$

(b) La operación de los controles internos a lo largo del periodo."

"Procedimientos sustantivos son pruebas realizadas para obtener evidencia de auditoría para detectar 
representaciones erróneas de importancia relativa en los estados financieros, $y$ son de dos tipos:

(a) Pruebas de detalles de transacciones y saldos; $y$

(b) Procedimientos analiticos".

Comunicación de resultados: antes de concluir con la auditoría se efectúa la revisión de hechos subsecuentes o posteriores. Finalmente se elabora el informe de auditoría que a base de la Norma Internacional de Auditoría NIA - 700 trata de la responsabilidad que tiene el auditor de formarse una opinión sobre los estados financieros. En Ecuador se debe presentar ante la Superintendencia de Compañías un informe de auditoría sobre estados financieros en el mes de abril, y en el mes de julio, el informe de cumplimiento tributario conocido como ICT al Servicio de Rentas Internas (SRI), con la opinión del auditor sobre los saldos impositivos presentados por el contribuyente. También trata de la estructura y el contenido del informe de auditoría emitido como resultado de una auditoría de estados financieros, existen cuatro tipos de opinión que pueden ser resultado de una auditoría a estados financieros, así tenemos:

Tabla 5.

Tipos de opinión en un informe de Auditoría

\begin{tabular}{|l|l|}
\hline TIPOS DE OPINIÓN & \multicolumn{1}{c|}{ DEFINICIONES } \\
\hline $\begin{array}{l}\text { Opinión limpia o sin } \\
\text { salvedades }\end{array}$ & $\begin{array}{l}\text { Cuando el auditor concluye que los estados financieros dan un punto de vista } \\
\text { verdadero y razonable (o están presentados razonablemente, respecto de todo lo } \\
\text { importante), de acuerdo con el marco conceptual para informes financieros identifi- } \\
\text { cados. }\end{array}$ \\
\hline $\begin{array}{l}\text { Opinión con } \\
\text { salvedades }\end{array}$ & $\begin{array}{l}\text { Cuando el auditor concluye que no puede expresarse una opinión limpia pero que el } \\
\text { efecto de cualquier desacuerdo con la administración, o limitación en el alcance no } \\
\text { es tan importante y omnipresente como para requerir una opinión adversa o una } \\
\text { abstención de opinión. Una opinión con salvedad debería expresarse como "excepto } \\
\text { por" los efectos del asunto al que se refiere la calificación. }\end{array}$ \\
\hline $\begin{array}{l}\text { Abstención de } \\
\text { opinión }\end{array}$ & $\begin{array}{l}\text { Debería expresarse cuando el posible efecto de una limitación en el alcance es tan } \\
\text { importante y omnipresente que el auditor no ha podido obtener suficiente evidencia } \\
\text { apropiada de auditoría y consecuentemente no puede expresar una opinión sobre } \\
\text { los estados financieros. }\end{array}$ \\
\hline Opinión adversa & $\begin{array}{l}\text { Debería expresarse cuando el efecto de un desacuerdo es tan importante y omni- } \\
\text { presente para los estados financieros que el auditor concluye que una salvedad al } \\
\text { dictamen no es adecuada para revelar la naturaleza equívoca o incompleta de los } \\
\text { estados financieros. }\end{array}$ \\
\hline
\end{tabular}


Para culminar, un informe de auditoría debe contener a base de la Norma Internacional de Auditoría 700 "El dictamen del auditor sobre los estados financieros", donde con tres párrafos fundamentales, se constituye en modelo de informe de auditoría.

El primer párrafo es una introducción donde el dictamen del auditor deberá identificar los estados financieros de la entidad que han sido auditados, incluyendo la fecha y el período cubierto por los estados financieros. El dictamen deberá incluir una declaración que los estados financieros son responsabilidad de la administración de la entidad, y una declaración que la responsabilidad del auditor es expresar una opinión sobre los estados financieros basada en la auditoría.

El segundo párrafo deberá describir el alcance de la auditoría declarando que la misma fue conducida de acuerdo con las normas internacionales de auditoría o de acuerdo con normas o prácticas nacionales relevantes según lo apropiado. "Alcance" se refiere a la capacidad del auditor de llevar a cabo los procedimientos de auditoría considerados necesarios en la circunstancias.

En el tercer párrafo el dictamen del auditor deberá declarar claramente su opinión respecto a si los estados financieros dan un punto de vista verdadero y razonable (o están presentados razonablemente, respecto de todo lo importante) de acuerdo con el marco conceptual para informes financieros y donde sea apropiado si los estados financieros cumplen con los requisitos legales.
Los términos usados para expresar la opinión del auditor "dan un punto de vista verdadero y razonable" o "presentan razonablemente, respecto de todo lo importante", y son equivalentes. Ambos términos indican, entre otras cosas, que el auditor considera solo aquellos asuntos que son de importancia relativa para los estados financieros. Batallas W. (2010).

De la misma forma se debe tener en cuenta que a partir del año 2014 aquellas empresas que se dedican al segmento de la construcción, además de presentar los informes de Auditoría anteriormente mencionados, deberán presentar el informe de lavado de activos.

\section{Conclusiones}

El auditor externo debe ejecutar su trabajo basándose en los parámetros establecidos en su ámbito profesional, considerando oportunamente leyes y reglamentos que amparan el campo contable, financiero y tributario. Debe recomendar a los departamentos contables que para efectuar toma de decisiones, las organizaciones deben tener una contabilidad financiera, mas no una contabilidad fiscal, como hoy en día se lo efectúa.

El auditor no debe ser considerado el "policía empresarial", sino más bien, su imagen debe relacionarse a la de un valioso asesor empresarial; brindando sus conocimientos como valor agregado, tomando en cuenta el riesgo en los procesos y las debilidades en sus controles y brindando soluciones inmediatas en el transcurso de su prestación de servicios. 


\section{Referencias Bibliográficas}

- Documento PDF A_Aud Fin Desarrollo Materia_BBadillo_Sept 09 Maestría en Auditoría y Finanzas Universidad Tecnológica Equinoccial.

- Domínguez, Borrajo M. (2002). La Auditoría interna y externa, Bogotá, Colombia, Editorial Continente.

- International Federation of Accountants, tomado de www.ifac.org

- Ley de Compañías del Ecuador.

- Mandariaga, J. M. (2011). Fundamentos de Auditoría Externa, Sevilla España, Editorial Mcgraw Hill.

- Norma Internacional de Auditoría NIA - 12 "Procedimientos analíticos".

- Norma Internacional de Auditoría NIA - 13 "El dictamen del auditor sobre los estados financieros".

- Norma Internacional de Auditoría NIA - 300 "Importancia relativa o materialidad en la planificación y ejecución de la auditoría".

- Norma Internacional de Auditoría NIA - 700 "Formación de la opinión y emisión del informe de auditoría sobre los estados financieros".

- Portal de Normas Internacionales de Información Financiera, tomado de www.iasb.org

- Superintendencia de Compañías, tomado de www.supercias.gob.ec

- Whittington O. R, Pany K. (2005). Fundamentos de Auditoría, 14 edición, México, Editorial Mcgraw Hill. 